\title{
ASPECTOS FUNCIONAIS DA CONSTRUÇÃO NOMINALIZADORA DE PARTICÍPIO PRESENTE
}

\section{FUNCTIONAL ASPECTS OF PRESENT PARTICIPLE NOMINALIZING CONSTRUCTION}

\section{RESUMO}

Fernando da Silva Cordeiro ${ }^{1}$ Edvaldo Balduino Bispo ${ }^{2}$ Tratamos aqui de aspectos funcionais da construção responsável pela formação de adjetivos em nte no português brasileiro a partir de uma base verbal, representada formalmente por $\left[[\mathrm{X}]_{\mathrm{V}}\right.$ $n t e]_{\text {ADj. }}$. O objetivo é analisar questões de natureza semântica, textual-discursiva, sociointeracional e cognitiva, implicadas na ocorrência desses adjetivos em situação real de uso da língua. Fundamentamo-nos teoricamente na Linguística Funcional Centrada no Uso e em contribuições da Gramática de Construções. Os dados empíricos provêm do Corpus Discurso \& Gramática, seções Natal e Rio de Janeiro. Nossos achados mostram que (i) adjetivos em -nte exibem baixa agentividade e nem sempre guardam transparência com o sentido do verbo-base; (ii) assumem uma pluralidade de funções textual-discursivas, a exemplo de subcategorização referencial e progressão discursiva; (iii) apresentam usos (inter)subjetivos e relacionam-se a estratégias de negociação de sentido; (iv) envolvem projeções metafóricas e metonímicas.

PALAVRAS-CHAVE: Aspectos funcionais. Adjetivo deverbal. Linguística Funcional Centrada no Uso. Gramática de Construções.

\begin{abstract}
We discuss the functional aspects of the construction that forms adjectives with -nte in Brazilian Portuguese, formalized as $\left[[\mathrm{X}]_{\mathrm{V}}-n t e\right]_{\mathrm{ADJ}}$. We aim to analyze semantic, discourse, sociointeractional and cognitive issues in the instances of these adjectives in real situations of interaction. Our theoretical support is the Linguística Funcional Centrada no Uso (LFCU) and the Construction Grammar. The database is the Corpus Discurso \& Gramática, sections Natal and Rio de Janeiro. Our findings show that (i) adjectives with -nte exhibit low agentivity and do not always maintain transparency with the sense of the base verb; (ii) they assume many of textual-discursive functions, such as referential subcategorization and discursive progression; (iii) they have (inter)subjective uses and are related to meaning negotiation strategies; (iv) they involve metaphorical and metonymic projections.
\end{abstract}

KEYWORDS: Functional aspects. Deverbal adjective. Linguística Funcional Centrada no Uso. Construction Grammar.

\section{INTRODUÇÃO}

Foco deste artigo, o que chamamos de particípio presente consiste em uma forma preservada do latim, marcada pelo sufixo - nte. Ele fazia parte do paradigma flexional dos verbos

\footnotetext{
${ }^{1}$ Mestre em Estudos da Linguagem pelo Programa de Pós-graduação em Estudos da Linguagem (UFRN). E-mail: nandocordeiro1@gmail.com.

${ }^{2}$ Doutor em Estudos da Linguagem. Professor do Departamento de Letras e do Programa de Pós-graduação em Estudos da Linguagem, Universidade Federal do Rio Grande do Norte. E-mail: edbbispo@gmail.com.
} 
latinos, contudo verifica-se no português brasileiro que esse sufixo integra o paradigma derivacional, atuando na formação de nomes (substantivos e adjetivos) a partir de bases verbais. A premissa de que mudanças na forma acarretaram mudanças na função que esses nomes exercem nos seus variados contextos de usos motivou trabalhos como o de Oliveira e Oliveira (2009) e, mais recentemente, o de Cordeiro (2017), cujas análises dão conta, respectivamente, da gramaticalização do particípio presente e da existência de uma construção subjacente aos nomes terminados em -nte: a construção nominalizadora de particípio presente, representada pelo padrão formal $\left[[\mathrm{X}]_{\mathrm{V}}-n t e\right]_{\mathrm{ADJ}}$.

Focalizamos, aqui, particularmente, os adjetivos formados por essa construção e que sintaticamente integram um Sintagma Nominal (SN). Isto é, analisamos adjetivos terminados em -nte na função de adjunto adnominal, conforme exemplificado em (1), (2) e (3).

(1) "ele tava com a mulher... três filhos... um filho... esses três filhos brilhantes assim.... gênios...(D\&G Natal, língua falada)

(2) "Um dos momentos mais emocionantes foi quando subi uma duna de areia" (D\&G Natal, língua escrita)

(3) "Este é um outro ponto importante, isto é, cada papel [...] oferece uma trama" (D\&G Natal, língua escrita)

Considerando existir uma construção que licencia as instâncias de uso desses adjetivos, objetivamos analisar aspectos semânticos, textual-discursivos, pragmáticos e cognitivos implicados nas instanciações dessa construção em dados da língua em uso. De modo mais específico, buscamos: (i) caracterizar semanticamente as bases verbais desses adjetivos no que diz respeito ao grau de atividade/intencionalidade que denotam; (ii) analisar o grau de transparência semântica entre adjetivo e verbo-base; (iii) explicitar o papel textual-discursivo desses adjetivos nos contextos em que ocorrem e, por último, (iv) discutir a atuação dos processos sociointeracionais de subjetividade, intersubjetividade e inferência sugerida, além de operações metafóricas e metonímicas nas ocorrências dos adjetivos analisados.

Para tanto, recorremos à Linguística Funcional Centrada no Uso (LFCU), conjunção teórica de pressupostos do funcionalismo linguístico e da Linguística Cognitiva, assim como a contribuições da Gramática de Construções. Assumimos, pois, que a codificação linguística é diretamente motivada pelo uso que os falantes fazem da língua nas diversas situações de interação em que estão inseridos e por processos cognitivos que subjazem à linguagem (MARTELOTTA, 2011). Desse modo, reafirmamos a premissa de que aspectos da forma estão intimamente ligados a aspectos da função. O conceito de construção, tal qual definido por Goldberg (1995; 2006), ilustra bem esse pressuposto na medida em que implica o pareamento de forma-função ${ }^{3}$, isto é, a associação convencionalizada entre algum elemento formal e algum significado, alguma função pragmática ou alguma estrutura informacional (FURTADO DA CUNHA; BISPO; SILVA, 2013).

A fonte dos dados empíricos aqui utilizados é o Corpus Discurso \& Gramática - a língua falada e escrita na cidade de Natal (FURTADO DA CUNHA, 1998) e no Rio de Janeiro (VOTRE; OLIVEIRA, 1995). Identificamos todas as ocorrências de adjetivos terminados em nte e as analisamos sob os matizes anteriormente identificados conforme os propósitos desta pesquisa. A busca resultou num total de 199 ocorrências, as quais foram distribuídas segundo a semântica do verbo-base, como se verifica na seção 2. Para os demais aspectos, não foi necessário organizar quantitativamente os dados. Destacamos que foram desprezados adjetivos em função predicativa.

Nossa abordagem é eminentemente qualitativa, visto que se presta a explicar o fenômeno linguístico investigado sob variados matizes (semântico, textual-discursivo, pragmático, cognitivo), considerando a interseção e a relação dialógica entre eles.

\footnotetext{
${ }^{3}$ Usamos o termo função em vez de significado (meaning) por guardar maior compatibilidade com a abordagem teórica aqui assumida e por ele incluir aspectos semântico-cognitivos e discursivo-pragmáticos.
} 
Organizamos este artigo em cinco seções: na primeira, apresentamos com mais detalhes o embasamento teórico-metodológico que sustenta nossas discussões; na segunda e terceira seções, discutimos aspectos semântico-discursivos relacionados aos adjetivos em -nte; na seção 4, tratamos da atuação de aspectos sociointeracionais e cognitivos nos usos desses elementos; na última seção, resumimos os principais achados da pesquisa e suas contribuições para a descrição do português brasileiro contemporâneo.

\section{Linguística Funcional Centrada no Uso e Gramática de Construções}

Cunhado no âmbito do grupo Discurso \& Gramática, o termo Linguística Funcional Centrada no Uso (LFCU) é uma tendência de estudos de natureza funcional-cognitivista, pois conjuga pressupostos do funcionalismo linguístico norte-americano e da Linguística Cognitiva. Conforme essa abordagem, os usos linguísticos resultam de modelos convencionalizados com base na interface linguagem, cognição e ambiente sócio-histórico. A inter-relação dessas três dimensões motiva a fixação de padrões gramaticais, via ritualização, a partir de ambientes interacionais específicos (MARTELOTTA, 2011; FURTADO DA CUNHA; BISPO, 2013).

Nessa perspectiva, a linguagem é compreendida como um "um complexo mosaico de atividades comunicativas, cognitivas e sociais estreitamente integrado a outros aspectos da psicologia humana" (TOMASELLO, 1998, p. ix). A língua, como parte desse mosaico, é vista como um código parcialmente arbitrário, dada sua adaptabilidade às necessidades interacionais, sociais e cognitivas dos usos que dela fazemos. Nos dizeres de Bybee (2010), consiste em um "sistema adaptativo complexo". Dito de outro modo, a língua é um "objeto maleável”, uma vez que se sujeita às pressões do uso, salientando também a atuação de processos cognitivos de domínio geral na codificação linguística. Deriva dessa abordagem funcionalista uma concepção de gramática como conjunto de padrões linguísticos regulares aberto, fortemente suscetível e intensamente afetado pelo uso (MARTELOTTA, 2011).

Estudos embasados na LFCU têm utilizado muito frequentemente formulações da Gramática de Construções (GC), a qual representa uma vertente de estudos em Linguística Cognitiva. Para a GC, a unidade básica da língua é a construção. Por construção, compreende-se o pareamento simbólico e convencionalizado de forma-função, como já explicitado anteriormente. Goldberg (2006, p. 5) salienta: "Qualquer padrão linguístico pode ser reconhecido como uma construção", ou seja, desde morfemas até a organização textual, passando por padrões de estrutura argumental, podem ser considerados uma construção, desde que tenham um conteúdo semântico-pragmático a ele associado. O principal postulado da GC é que as línguas são, na verdade, complexas e dinâmicas redes de construções, pois elas são a unidade básica da gramática de uma língua. As diversas construções de uma língua diferenciam-se somente em termos de especificação, tamanho e conceito. Croft (2001) estabelece que, em uma construção, estão associadas duas dimensões: a da forma e a do significado (função), estando as duas interligadas por elo de correspondência simbólica. $\mathrm{O}$ autor atribui ao polo da forma as propriedades fonológicas, morfológicas e sintáticas e ao polo da função as propriedades semânticas, discursivas e pragmáticas. Neste artigo, damos especial atenção a estas três últimas propriedades, já que nosso intuito é discutir aspectos relativos à função da construção.

Particularmente no que diz respeito às propriedades semânticas, analisamos as bases verbais de que se originam os adjetivos em -nte, considerando os eventos por elas denotados e a relação de transparência semântica (ou não) entre os usos desses adjetivos e essas bases verbais. Para tanto, recorremos à classificação semântica de verbos elaborada por Tavares (2007) com base na proposta por Schlesinger (1995) e Quirk et al. (1972), citados pela autora. Schlesinger listou onze categorias semântico-pragmáticas de verbos, diferenciadas pelo grau de atividade e agentividade que indicam e o evento representado no mundo. Tavares reorganizou as categorias adicionando à classificação mais quatro tipos de verbos, resultando numa categorização mais 
detalhada. Reproduzimos, a seguir, o quadro com os tipos semântico-pragmáticos propostos pela autora.

\begin{tabular}{|l|l|}
\hline \multicolumn{1}{|c|}{ Categoria } & \multicolumn{1}{|c|}{ Descrição } \\
\hline Momentâneo & $\begin{array}{l}\text { Refere-se à atividade repentina de curta duração: Saltar, chutar, } \\
\text { bater, derrubar, golpear, quebrar (intencional) }\end{array}$ \\
\hline Atividade específica & $\begin{array}{l}\text { Evoca uma imagem específica: Escrever, jogar, beber, desenhar, } \\
\text { nadar, andar, sorrir }\end{array}$ \\
\hline Dicendi & $\begin{array}{l}\text { Precede a citação ou o discurso direto: Dižer, falar, responder, } \\
\text { ordenar, perguntar }\end{array}$ \\
\hline Atividade difusa & $\begin{array}{l}\text { Não evoca uma imagem específica: Aposentar-se, trabalhar, } \\
\text { aprender, mendigar, estudar }\end{array}$ \\
\hline Instância & $\begin{array}{l}\text { Posição corporal estática: Deitar(-se), recostar(-se), sentar(-se), } \\
\text { pousar(-se), reclinar(-se) }\end{array}$ \\
\hline Estímulo mental & $\begin{array}{l}\text { O sujeito da oração é o estímulo da experiência mental de } \\
\text { outrem: Impressionar, agradar, surpreender, assustar, espantar, } \\
\text { aborrecer }\end{array}$ \\
\hline Evento transitório intencional & $\begin{array}{l}\text { Indica se o sujeito permanece em certo lugar: Permanecer, residir, } \\
\text { situar, estar (em algum lugar) }\end{array}$ \\
\hline $\begin{array}{l}\text { Evento transitório } \text { não- } \\
\text { intencional }\end{array}$ & $\begin{array}{l}\text { Refere-se a ações não-intencionais: Morrer, cair, desmaiar, } \\
\text { adormecer, acordar, quebrar (não-intencional) }\end{array}$ \\
\hline Processo & $\begin{array}{l}\text { Mudança não-intencional sofrida por um corpo (mais ou } \\
\text { menos animado): Deteriorar, crescer, amadurecer, transformar, ferver, } \\
\text { congelar }\end{array}$ \\
\hline Experimentação mental & $\begin{array}{l}\text { O sujeito da oração é o experienciador: Adorar, odiar, desejar, } \\
\text { pensar, lembrar, entender }\end{array}$ \\
\hline Distanciamento ou suavização da opinião: Achar, pensar \\
\hline Etenuação & $\begin{array}{l}\text { Representa relações assinaladas pelos homens em seu } \\
\text { processo de percepção da realidade: identidade, analogia, } \\
\text { comparação, posse, causa, finalidade, consequência etc.: } \\
\text { Depender de, merecer, precisar, servir como, assemelhar-se, causar, } \\
\text { igualar, ter (posse), determinar, faltar (algo), errar, resultar de/ em, } \\
\text { relacionar-se com, custar }\end{array}$ \\
\hline Relacional & Sensação física: Machucar-se, doer, ferir, sentir, sofrer \\
\hline Estado & Ter, haver, existir. \\
\hline Quadro 1-Classificação semântica dos verbos \\
\hline Exial
\end{tabular}

Fonte: Tavares (2007, p. 101)

Apoiados também numa visão mais cognitivista da estruturação semântica, consideramos que as construções estão ligadas a frames interpretativos (FILLMORE, 1982). O conceito de frame remete à estruturação conceptual das experiências humanas estocadas nas memórias em cenas. Um frame representa a cena de fundo subjacente a uma dada expressão linguística (FRIED, 2015). Tratar a semântica de uma construção em termos de frames pode ser produtivo no sentido de que os frames refletem a compreensão de como se constrói o significado de uma construção e de como ela pode ser usada contextualmente. Além disso, uma construção pode evidenciar o modo como os frames são (re)elaborados e como a informação semântica se estrutura na mente do falante de uma determinada língua.

$\mathrm{Na}$ LFCU, o discurso consiste nas estratégias sociopragmaticamente orientadas de produção de sentidos e organização dos enunciados (FURTADO DA CUNHA; BISPO; SILVA, 2013). Por isso, quando nos referimos às propriedades discursivas da construção em análise, falamos de seu uso como instância de organização da superfície textual, como ato motivado 
tendo em vista os propósitos do falante num determinado contexto. O trabalho de Silva (2011) sobre adjetivos adjuntos trouxe-nos à luz a atuação de palavras dessa classe na organização textual-discursiva dos enunciados. Afastando-se da visão tradicional de que os adjetivos somente codificam atributos dos nomes a que estão relacionados, o autor explora a relevância dos adjetivos, incluindo os que pesquisamos, para o discurso nos mais diversos contextos comunicativos. Conforme os dados analisados por Silva, os adjetivos podem atuar na

a) subcategorização referencial, delimitando o conteúdo referencial do nome com que se relacionam;

b) topicalização discursiva, quando auxiliam na introdução de um novo tópico discursivo;

c) focalização referencial-discursiva, assim que configuram o elemento referido e/ou o conteúdo textual/discursivo numa dada perspectiva;

d) progressão discursiva, à medida em que cooperam nos movimentos prospectivos e/ou retrospectivos do conteúdo informacional; e

e) argumentação, quando contribuem para os procedimentos retórico-argumentativos.

De importância fundamental para a LFCU, os aspectos sociointeracionais são motivações importantes para a estruturação linguística e para o processo de mudança da língua. Compreendemos como sociointeracionais aspectos ligados aos propósitos comunicativos do falante, à sua relação com o interlocutor, aos papéis sociais que ambos assumem e a todo o contexto sócio-histórico em que interagem. Situam-se aí as questões relacionadas à expressão da subjetividade do falante e de sua inter-relação com o interlocutor com vistas ao alcance de propósitos comunicativos. Traugott e Dasher (2002), citando Halliday e Hasan (1976), falam, então, em significados intersubjetivos, constituídos a partir da relação entre o falante/escritor com seu(s) interlocutor(es) e da postura que aquele assume em relação a este, no que diz respeito à polidez, a estratégias retóricas e a informações compartilhadas, por exemplo.

Segundo Traugott (2012), na interação, o falante utiliza marcadores que codificam sua posição subjetiva e/ou direcionam a atenção do interlocutor para essa posição. A autora considera tanto a subjetivização quanto a intersubjetivização como processos de desenvolvimento desses marcadores, um caso típico de polissemia das expressões multifuncionais. Em outro patamar, subjetivização e intersubjetivização também são considerados processos de mudança semântica, já que os falantes atribuem sentidos (inter)subjetivos a marcadores de significado nãointersubjetivos, o que pode resultar posteriormente em mudança linguística. Neste artigo, não analisamos a trajetória de desenvolvimento dos adjetivos como expressões (inter)subjetivas, mas tratamos sincronicamente da manifestação da subjetividade do falante e de relações intersubjetivas implicadas nas ocorrências de adjetivos deverbais.

Outro fator de ordem interacional que aqui utilizamos é a inferência sugerida (invited inference), conforme discutida por Traugott e Dasher (2002) e Traugott (2010, 2012). Refere-se ao processo intersubjetivo em que o falante, ao empregar uma dada expressão linguística, conta com a colaboração do ouvinte para apreender o significado pretendido. A inferência sugerida está relacionada às necessidades comunicativas dos falantes e motiva a criação de novos pares de forma-sentido, à medida que os atos comunicativos realizados exigem a interpretação de um determinado elemento linguístico de modo diferente do comum. Esse novo uso pode acarretar convencionalização e rotinização, de modo que essa associação passa por uma reanálise estrutural e/ou semântica.

Atreladas a esses fatores interacionais e a eles subjacentes estão operações cognitivas, como projeções metafóricas e metonímicas. A metáfora representa um caso de operações entre domínios cognitivo-conceituais, imprescindível no processamento mental e no intercâmbio de significação comunicativa (FURTADO DA CUNHA; BISPO, 2013). Conforme Lakoff e Johnson (1999), caracteriza-se pelo mapeamento entre domínios conceituais, em que determinadas noções de um domínio são projetadas em outro. Ou seja, um conceito é formulado em termos de outro pelo fato de compartilharem alguma(s) correspondência(s) conceitual(is). 
Já a metonímia, segundo Lakoff e Turner (1989), constitui um mapeamento dentro de um mesmo domínio conceitual, de modo que uma entidade de um domínio pode ser utilizada para se reportar a outra entidade desse mesmo domínio, como se dá na relação parte-todo. Trata-se de um componente básico do nosso aparato racional, ou seja, do nosso sistema cognitivo. É focalizada como uma questão de conceitualização, no sentido de que, em parte, responde pelo processamento de determinadas formações conceituais.

Uma vez explicitadas as bases teórico-metodológicas que dão suporte à discussão aqui empreendida, passemos à análise de ocorrências de adjetivos em - nte flagradas em nosso corpus.

\section{A (não) transparência semântica entre adjetivo e verbo-base}

Segundo Fillmore (1982), o significado dos nomes deverbais está relacionado a frames interpretativos diretamente associados à semântica do verbo. Por esse motivo, identificamos os tipos de verbos recrutados pela construção e, em seguida, verificamos se o adjetivo em -nte preserva aspectos semânticos do verbo de que se originou. Organizamos esses verbos de acordo com a classificação proposta por Tavares (2007), que contempla quinze categorias dispostas em um continum conforme o grau de atividade expresso pelo verbo. Nossa hipótese era que os adjetivos em -nte fossem mais agentivos, ou seja, atribuíssem agentividade ao nome a que se referem. Esperávamos que verbos com graus maiores de atividade fossem mais frequentes para a construção, pois as gramáticas relacionam o sufixo - nte como um dos sufixos responsáveis pela formação de nomes agentivos. Eis o resultado.

\begin{tabular}{lrr}
\hline TIPO SEMÂNTICO & QUANTIDADE & $\begin{array}{r}\text { PERCENTUAL } \\
\mathbf{( \% )}\end{array}$ \\
\hline Momentâneo & 1 & 2,70 \\
\hline Atividade específica & 1 & 2,70 \\
\hline Dicendi & 1 & 2,70 \\
\hline Atividade difusa & 6 & 16,22 \\
\hline Instância & 0 & 0,00 \\
\hline Estímulo mental & 5 & 13,51 \\
\hline Evento transitório-intencional & 1 & 2,70 \\
\hline Evento transitório não- & 3 & 8,11 \\
intencional & & 2,70 \\
\hline Processo & 1 & 8,11 \\
\hline Experimentação mental & 3 & 0,00 \\
\hline Atenuação & 0 & 24,32 \\
\hline Relacional & 9 & 0,00 \\
\hline Sensação corporal & 0 & 10,81 \\
\hline Existência & 4 & 5,41 \\
\hline Estado & 2 & $\mathbf{1 0 0 , 0 0}$ \\
\hline TOTAL & $\mathbf{3 7}$ & \\
\hline
\end{tabular}

Tabela 1: Ocorrências de $\left[[\mathrm{X}]_{\mathrm{V}}-n t e\right]_{\mathrm{ADJ}}$ por tipo semântico do verbo-base Fonte: Cordeiro (2017, p. 71)

Conforme a tabela 1, encontramos 37 bases verbais diferentes, ou seja, as 199 ocorrências (tokens) dos adjetivos no corpus representam 37 tipos distintos (types). Os números apontam que os verbos do tipo relacional são os mais recorrentes no conjunto de dados. Esses verbos são aqueles ligados à expressão de relações percebidas pelo homem em sua interação com o mundo: posse, correspondência, comparação, analogia, entre outras. As ocorrências em (4) e (5) exemplificam bases verbais do tipo relacional. $\mathrm{O}$ adjetivo contrastante, derivado de contrastar, é usado pelo informante para ressaltar as diferenças entre duas cores, expressando a percepção humana em 
relação ao referido objeto. Cabe a mesma classificação ao verbo-base de distante, em (5). Também se trata da percepção do falante quando ele indica o afastamento de suas lembranças naquele momento, utilizando a perspectiva espacial que o adjetivo denota.

(4) "você escolhe umas duas cores de papel... duas cores contrastantes..." (D\&G Rio, língua falada)

(5) "eu só me lembro das partes assim... uma coisa tão distante da outra" (D\&G Natal, língua falada)

Em segundo e terceiro lugares do nosso levantamento ficaram, respectivamente, os verbos de atividade difusa e os de estímulo mental. Os verbos de atividade difusa correspondem aos que codificam ações mais gerais, com menor grau de intencionalidade e de envolvimento do sujeito, menos específicos em relação à cena evocada, com menos restrições quanto às características dos participantes, caso do verbo aconchegar, base do adjetivo aconchegante, destacado em (6). Já os verbos de estímulo mental são aqueles cujo sujeito (algo ou alguém) provoca uma experiência mental em outro participante da cena evocada, caso exemplificado em (7), em que um fato é responsável pela comoção do falante.

(6) "o telhado... tem estilo europeu... lugar bastante aconchegante... interessante" (D\&G Rio, língua falada)

(7) "uma coisa que... também me...que eu lembro como um fato curioso e bonito... comovente que me emocionou muito" (D\&G Natal, língua falada)

Deduzimos, pelos resultados apresentados, que a construção seleciona verbos de natureza semântica diversa, desde aqueles com maior grau de atividade e envolvimento do sujeito até os verbos de estado, de baixa agentividade e intencionalidade. Contudo, são mais frequentes as bases verbais com graus baixos de atividade, já que a maioria dos verbos-base encontrados se situam cada vez mais próximo do polo estativo do continuum (parte inferior da tabela). Essa constatação, portanto, vai de encontro à nossa hipótese. Provavelmente, os traços semânticos [+ agentividade] $[+$ intencionalidade $]$ podem favorecer a flutuação categorial do adjetivo terminado em -nte para usos como substantivo, que não foram analisados nesta pesquisa.

Para determinar o grau de atividade da base verbal, consideramos os seguintes traços semânticos, dispostos em um continuum: [+- agentividade], [+- intencionalidade], [+dinamicidade], [+- telicidade] e [+- pontualidade]. Nesse caso, os adjetivos deverbais em -nte são, conforme os dados analisados, marcados pelos traços semânticos [- agentividade], [intencionalidade], [- telicidade], [- pontualidade], sendo [+- dinamicidade] o único traço que varia nos diversos types encontrados. Esses resultados vão de encontro ao fato de que, tradicionalmente, aos nomes formados pelo acréscimo do sufixo - nte é atribuída a demarcação do sujeito de um evento principal na voz ativa, envolvendo semanticamente uma ação ou processo que exige (pelo menos) um participante necessariamente animado (FRIED, 2008; 2009).

É oportuno observar que, em alguns casos, o adjetivo não herda todas as propriedades semânticas do verbo que lhe serviu de base. Vejamos o caso de gritante em (8), que tem gritar como base. Para esse verbo, pressupõe-se um sujeito agente e uma ação intencional. Entretanto, o adjetivo dele derivado não exibe as mesmas especificações semânticas, mas apresenta usos abstratizados, modificando um substantivo marcado por traços [- humano] e [- animado].

(8) “cores assim suaves... não são nada fortes, sabe? nada muito gritante...” (D\&G Natal, língua falada)

Essa falta de transparência entre o sentido do verbo e o uso do adjetivo em -nte dele derivado reforça a ideia de que o sentido de uma construção não necessariamente decorre da soma do sentido de suas partes componentes, embora cada uma das partes concorra para a instauração desse sentido (ROSÁRIO; OLIVEIRA, 2016). Casos há, porém, de compatibilidade semântica entre o verbo-base e o adjetivo. Desse modo, podemos falar em um continuum de usos dos adjetivos de particípio presente, colocando, de um lado, aqueles em que a semântica verbal é mais proeminente e, de outro, aqueles usos em que o sentido do verbo é pouco transparente. 
Nos usos dos adjetivos destacados em (9) e (10), por exemplo, o significado remete à semântica da base verbal. Percebemos, nesses casos, transparência entre a semântica do verbo e a do adjetivo. Em (11), o significado do adjetivo também parece diretamente associado ao significado da base verbal, contudo, trata-se de um uso pragmaticamente motivado de pensante, visto que não se refere somente a um indivíduo que pensa, mas que apresenta certo grau de esclarecimento/ senso crítico. Assim, compreendemos haver aí um pequeno distanciamento da semântica verbal visto ela, sozinha, não ser suficiente para explicar os propósitos do falante na ocasião.

(9) “coloco pra secar num papel... Como é que chama... papel... absorvente" (D\&G Natal, língua falada)

(10) "uma coisa que... também me... que eu lembro como um fato curioso e bonito... comovente" (D\&G Natal, língua falada)

(11) "uma Assembléia de Deus totalmente restrita... que corta assim... Todas as asas do indivíduo pensante" (D\&G Natal, língua falada)

Já em (12), o adjetivo competente não tem seu significado deduzível da soma do significado de suas partes componentes (no caso, a base verbal e o sufixo), havendo, assim, perda de composicionalidade. Isso pode ser consequência, entre outras coisas, da alta frequência e da expansão de seus contextos de uso.

(12) "porque é menor... faz... vai pra FEBEM... né? esses negócios... um órgão competente...” (D\&G Natal, língua falada)

Fried (2008; 2009) identificou que, em alguns casos, o significado composicional provido pela estrutura morfossemântica é substituída por um significado especializado que não é totalmente previsível pela composição do adjetivo. É o que encontramos também no PB, no caso de alguns adjetivos em - nte.

\section{A multifuncionalidade textual-discursiva de adjetivos em -nte}

Encontramos adjetivos adjuntivos licenciados pela construção nominalizadora de particípio presente em todas as funções discursivas elencadas por Silva (2011). Isso quer dizer que eles se apresentam como elementos multifuncionais do ponto de vista textual-discursivo, seja auxiliando a delimitação referencial do nome com que se relacionam, seja contribuindo para a coesão e/ou para a argumentação do falante em determinado texto.

A primeira função citada por Silva (2011) é a de subcategorização referencial, quando o adjetivo demarca um "recorte" no todo maior denotado pelo substantivo a que está vinculado. Nesses casos, o adjetivo age como um elemento capaz de modificar o substantivo ou delimitá-lo. As ocorrências de (13) a (15) demonstram instâncias de uso da construção em foco na delimitação do referente do nome a que se ligam. Em (13), o adjetivo inocentes atua na indicação de que a pena de morte se aplicaria a um determinado grupo de pessoas. Em (14) e (15), de modo parecido, os adjetivos dominante e protestante especificam melhor os substantivos classe e religião, respectivamente. Notamos que, nesses contextos, o adjetivo não funciona apenas como um mero atributo do substantivo, mas como um elemento importante para os propósitos comunicativos do falante na medida em que lhe permite identificar com exatidão um referente no discurso.

(13) "No Brasil, a pena de morte seria nada mais nada menos do que uma forma de matar pessoas inocentes..." (D\&G Natal, língua escrita)

(14) “A crise educacional é uma jogada política, não é interesse para a classe dominante ter uma população com consciência...” (D\&G Rio, língua escrita)

(15) "você sabe que a religião protestante... ela é bem dividida... né..." (D\&G Natal, língua falada)

Flagramos também usos de adjetivos atuando na cadeia tópica, amparando a introdução de tópicos discursivos, assim como exemplificado em (16), (17), (18) e (19). O emprego de interessante, nessas e em outras ocorrências de nosso corpus, deu-se para introduzir o relato de um 
fato/acontecimento. Essas situações representam o início de narrativas (recontadas ou de experiência pessoal), que integram o Corpus Discurso \& Gramática. Destacamos que esse emprego serve não apenas para a apresentação do que vai ser dito mas também para a atribuição de certa proeminência ao que será dito, chamando a atenção do interlocutor para os fatos que seguem.

(16) "no mesmo dia aconteceu uma coisa interessante porque... as muriçocas só paravam de aperriar quando a gente deixa a luz acesa [...] a gente terminou passando a noite acordada" (D\&G Natal, língua falada)

(17) "ele me mostrou uma coisa bem interessante que... pegou um béquer com meio d’água e colocou um pouquinho de cloreto de sódio..." (D\&G Natal, língua falada)

(18) "eu acho um fato interessante... né... foi como meu pai e minha mãe vieram se conhecer..." (D\&G Natal, língua falada)

(19) "ah... inclusive houve uma coisa super interessante... que... eu conheço uma pessoa que faz parte da associação de negros [...] eles estão reivindicando...” (D\&G Rio, língua falada)

Em se tratando da focalização referencial e discursiva, encontramos adjetivos em -nte contribuindo para o enquadramento de um dado referente na perspectiva adotada pelo falante. $\mathrm{Na}$ ocorrência (20), por exemplo, ao tratar de seu lugar preferido, o falante entende que a ideia de conforto é essencial para caracterizar o lugar ideal e por isso vale-se do adjetivo aconchegante. Em (21), também numa perspectiva subjetiva, ele avalia uma peça a que assistiu como emocionante. De forma semelhante, em (22), o referente é perspectivizado a partir de um ponto de referência pessoal, sobre o que falante considera adequado em termos de vestimenta: o adjetivo extravagante mostra, então, que determinadas roupas eram inadequadas. Nesses casos, o adjetivo serve para, de certo modo, ampliar a caracterização do referente, calcada na subjetividade.

(20) "Meu lugar preferido para se ficar é meu quarto [...] é um lugar arejado, aconchegante e agradável..." (D\&G Rio, língua escrita)

(21) "Na sexta-feira à noite houve a Noite de Talentos [...] e teve a apresentação de uma peça. [...] enfim, foi uma peça muito bonita, emocionante, que fez cair lágrimas..." (D\&G Natal, língua escrita)

(22) "foi pra uma loja comprar roupas... [...] ela tinha as roupas muito extravagante" (D\&G Natal, língua falada)

As ocorrências em (23) e (24), por sua vez, ilustram situações em que os adjetivos participais atendem a procedimentos retórico-argumentativos, função também muito recorrente no corpus, em que o adjetivo expressa a assunção de um ponto de vista por parte do falante, ressaltando-o. O uso de inteligente, em (23), auxilia a construção da opinião do informante em relação a um programa de TV, reforçada pela posição assumida na oração seguinte. De modo semelhante, o adjetivo importante, na amostra em (24), ancora o julgamento do informante sobre o tema liberdade.

(23) "é um programa inteligente... eu gosto... algumas entrevistas eu gosto" (D\&G Natal, língua falada)

(24) "eu sou uma pessoa assim que quero viver assim... independente [...] a liber/ a liberdade é uma coisa muito importante...” (D\&G Natal, língua falada)

Outra função a que servem os adjetivos formados pela construção em estudo consiste no auxílio à progressão discursiva, conforme exemplificado em (25), (26) e (27), estabelecendo relações de sequenciação espacial/textual e temporal entre porções do texto. $\mathrm{Na}$ função de sequenciador, especificamente, o adjetivo seguinte figura como elemento prototípico, pois essa função é desempenhada por ele em praticamente todas as suas ocorrências no corpus. Além disso, os adjetivos em -nte podem auxiliar os movimentos de retrospecção e prospecção de referência ao conteúdo informacional, assim como mostrado em (28) e (29). O adjetivo diferente, em (28), antecipa, de certa forma, o conteúdo informacional, de modo que o interlocutor já tenha uma ideia de como a aula era conduzida. Em (29), por uma vez, o adjetivo importante contribui para a retomada de parte da narrativa anterior da experiência do falante, atribuindo-lhe certo valor. 
(25) "No dia seguinte, voltou tristonho para casa, refez suas ideias, e não lembrará do acontecido" (D\&G Natal, língua escrita)

(26) "A água passa do lado depois de esborrotar e vai para a fase seguinte" (D\&G Natal, língua escrita)

(27) "no dia seguinte, tomaram café... foram brincar lá no pátio né..." (D\&G Rio, língua falada)

(28) "eram aulas bem... bem diferentes... [...] num era aquela aula metódica... né... eles expunham... certas vezes o aluno a debater....” (D\&G Natal, língua falada)

(29) "quando ele começou a sair com ela... as coisas que ele falava de mim... sabe? [...] isso

foi uma coisa muito importante da minha vida." (D\&G Rio, língua falada)

Os casos aqui analisados permitem-nos atestar, portanto, a multifuncionalidade dos adjetivos em -nte na organização textual/discursiva, conforme proposto por Silva (2011). Vejamos, agora, questões de ordem pragmática e cognitiva implicadas nos usos desses adjetivos.

\section{A atuação de processos sociointeracionais e cognitivos}

Baseados na premissa de que aspectos da situação comunicativa, tais como os participantes, suas características socioculturais, seus interesses comunicativos, entre outros, são determinantes para os usos linguísticos, discutimos aqui a atuação de processos sociointeracionais. Focalizamos, em especial, inferência sugerida e processos de subjetividade e intersubjetividade nos usos de adjetivos em -nte.

Ao interagirem, os falantes criam e negociam significados, amparados no conhecimento que compartilham ou supõem compartilhar e nas inferências que podem fazer no ato comunicativo. Essa criação e negociação de significados são potenciais motivadores para a expansão de usos de formas linguísticas, como se dá com os adjetivos de que nos ocupamos. Conforme expusemos em seções prévias, esses adjetivos nem sempre apresentam semântica diretamente relacionada à semântica do verbo-base, exibindo comportamento polissêmico, o que atesta a influência de fatores não apenas formais, mas também interacionais, para seu significado.

A ocorrência (8), retomada a seguir, ilustra situação em que o sentido atribuído ao adjetivo é negociado na interação. No caso analisado, o falante emprega gritante para caracterizar cores que pretende utilizar. Para a compreensão do sentido pretendido (chamativo, de destaque), o interlocutor não se orienta pela semântica do verbo-base, mas pelas pistas que o falante deixa, como, por exemplo, o emprego de "assim suaves... nada fortes...", e pelo conhecimento compartilhado acerca de tipos/ características de cores, aceitando o convite feito pelo falante para inferir a acepção com que o adjetivo é empregado. Assim, esse sentido é negociado, construído conjuntamente.

(8) "tudo bem cores assim suaves... não são nada... Fortes, sabe? Nada muito gritante" (D\&G Natal, língua falada)

Analisamos de modo semelhante a ocorrência em (1), repetida adiante. Considerar apenas a base verbal para o sentido do adjetivo neste contexto não forneceria uma interpretação adequada do uso que dele se faz. Assim, o falante sugere a seu interlocutor que brilhante seja compreendido como sinônimo de inteligente e prodigioso, dando proeminência a certa característica dos filhos, até porque o sentido literal neste caso culminaria numa incoerência: não existem indícios de um ser humano que brilha literalmente. A inferência sugerida se instaura quando o falante, caracterizando o referente a partir de seu próprio julgamento, procura garantir que o seu interlocutor consiga estabelecer a mesma relação entre o adjetivo e o sentido pretendido nesse contexto, fornecendo também pistas linguísticas, como o uso de “...assim... gênios... coisa assim...”.

(1) "ele tava com a mulher [...] esses três filhos brilhantes... assim... gênios... coisa assim... (D\&G Natal, língua falada) 
Também verificamos nesses usos aspectos (inter)subjetivos. Assim, por exemplo, o emprego de gritante e brilhantes, em (8) e (1), revela uma avaliação pessoal do falante em relação ao uso de determinada cor ou à inteligência de algumas pessoas (os filhos), respectivamente. Ou seja, mostra a expressão da subjetividade. Em (30), da mesma sorte, o uso de ignorante está relacionado à posição subjetiva do falante quanto à caracterização de pessoas que moram no interior, considerando-as menos suscetíveis a novidades, a mudanças, daí serem tomadas como de "mente mais fechada".

(30) "as pessoas do interior têm uma mente mais fechada... entende? São pessoas do

tipo... entre aspas... ignorantes... né? (D\&G Rio, língua falada)

Ocorrências de adjetivos em -nte também se relacionam à intersubjetividade no sentido de que implicam a consideração, por parte do falante, de seu interlocutor, seja na busca de monitorar sua atenção, direcionando-a a um dado aspecto, seja na intenção de negociar sentidos ou mesmo de ganhar-lhe a adesão a uma determinada questão. É o que parece claro nas instanciações em (13) e (18), aqui retomadas.

(13) "No Brasil, a pena de morte seria nada mais nada menos do que uma forma de matar pessoas inocentes..." (D\&G Natal, língua escrita)

(18) "eu acho um fato interessante... né... foi como meu pai e minha mãe vieram se conhecer...” (D\&G Natal, língua falada)

Em (13), trecho extraído de um relato de opinião em que o falante se manifesta contrário à implantação da pena de morte no Brasil, o emprego de inocente serve não apenas para explicitar esse posicionamento mas também para, de algum modo, buscar a anuência de seu interlocutor quanto a essa opinião. Já em (18), retirado de uma narrativa de experiência pessoal, o uso do adjetivo em destaque funciona tanto como expressão subjetiva do falante sobre o fato a ser relatado quanto para chamar a atenção de seu interlocutor para o que vai ser dito. Também há relações intersubjetivas implicadas nos casos ilustrados em (1) e (8), nos quais se dão estratégias de negociação de sentidos, calcadas em processos inferenciais, o que envolve, naturalmente, a participação ativa do interlocutor na construção e compreensão do sentido pretendido pelo falante.

É importante destacar que, estreitamente vinculadas a essas relações (inter)subjetivas e de negociação de sentidos e a elas subjacentes, estão operações cognitivas, sobretudo projeções metafóricas. Vejamos os casos dos adjetivos brilhante, em (1) e (31), e gritante, em (8).

(31) "se tem uma ideia brilhante e num é de acordo com eles... demite..." (D\&G Natal, língua falada)

As ocorrências com brilhante ilustram a metáfora conceitual INTELIGÊNCIA É BRILHO, calcada na associação entre o destaque perceptivo-visual, decorrente do ato de brilhar, e a noção de prodigiosidade. Assim, aquilo que está ligado à esfera da intelectualidade, de significação mais abstrata, pode ser expresso por meio da ação de brilhar, mais ligada à concretude, nesse caso, a nossas experiências sensoriais. Daí ser possível que, como posto em (31), uma ideia muito boa, inteligente, admirável, seja considerada brilhante. Em outro nível, essa metáfora se estende de tal modo que podemos atribuir a qualidade de brilhante a um ser humano, conforme se dá em (1).

Quanto ao adjetivo gritante, em (8), ele é usado com valor de intensidade, também por meio de uma projeção metafórica. Segundo pontuou Silva (2008, p. 225), "muitos intensificadores emergem de conceitos que designam, denotativamente, sensações/experiências biofísicas". Diferente de brilhante, cuja ação denotada não é naturalmente parte de nossas capacidades naturais, gritante está relacionado a uma ação essencialmente humana (gritar). Dessa forma, podemos associar a noção de intensificação presente em gritante à própria ação de gritar, resultando na metáfora INTENSIDADE É GRITO. A ideia de aumento/intensidade do som contida em gritar (algo do mundo físico) é transferida para outro domínio (o de chamar a atenção, de provocar destaque), ligado às relações sociais. 
É preciso lembrar que, como postula Kövecses (2002), o pensamento metafórico envolve o pensamento metonímico, uma vez que muitas metáforas podem ser motivadas por relações metonímicas. Nas ocorrências dos adjetivos brilhante e gritante, é possível recuperar que, antes da relação metafórica, existe inicialmente uma relação metonímica de causa-efeito. As ações denotadas por brilhar e gritar são possivelmente recrutadas para a expressão de conceitos como genialidade e intensidade porque têm como resultado imediato certo impacto sensorial. Dito de outro modo, essas ações têm como efeito o destaque perceptual.

\section{CONSIDERAÇÕES FINAIS}

Neste trabalho, analisamos funcionalmente adjetivos formados pela construção nominalizadora de particípio presente $\left[[\mathrm{X}]_{\mathrm{V}}-n t e\right]_{\mathrm{ADJ}}$. Falamos de propriedades semânticas, textualdiscursivas e pragmáticas dessa construção a partir de suas ocorrências em situações de uso efetivo da língua. Acerca de propriedades semânticas, destacamos que não há transparência total entre o adjetivo e o verbo-base, além de mostrarmos que verbos com baixos graus de atividade são mais frequentemente recrutados para a formação desses adjetivos. No tocante às propriedades textual-discursivas, concluímos que esses elementos são multifuncionais, contribuindo significativamente para o recorte referencial do SN que integram, para a organização do conteúdo informacional, para a manutenção da coesão textual e para a progressão discursiva. Vimos que processos sociointeracionais, a exemplo da negociação de sentidos, via inferência sugerida, e questões atinentes à expressão de subjetividade e relações intersubjetivas atuam em instâncias de uso da construção em foco. Observamos, por fim, que a esses processos interacionais subjazem operações cognitivas, particularmente projeções metafóricas e metonímicas. Os achados deste estudo, por um lado, representam contribuições à descrição da morfossintaxe do português contemporâneo sob a ótica funcionalista e, por outro lado, abrem possibilidades, de modo mais específico, para o tratamento de outros morfemas, e, em sentido amplo, para a análise do processo de nominalização.

\section{REFERÊNCIAS}

BYBEE, Joan L. Language, usage and cognition. Cambridge: CUP, 2010.

CORDEIRO, Fernando da Silva. Construção nominalizadora de particípio presente: uma abordagem funcional centrada no uso. 104f. Dissertação (Mestrado em Linguística Teórica e Descritiva) - Programa de Pós-graduação em Estudos da Linguagem, Universidade Federal do Rio Grande do Norte, Natal, 2017.

CROFT, William. Radical construction grammar: syntatic theory in typological perspective. Oxford: Oxford University Press, 2001.

FILLMORE, Charles J. Frame Semantics. In: The Linguistic Society of Korea (ed.), Linguistics in the Morning Calm. Seoul: Hanshin, 1982, p. 111-137.

FURTADO DA CUNHA, Maria Angélica (Org.) Corpus Discurso \& Gramática - a língua falada e escrita na cidade do Natal. Natal: EDUFRN, 1998.

; BISPO, Edvaldo Balduino. Pressupostos teórico-metodológicos e categorias analíticas da

Linguística Funcional Centrada no Uso. Revista do GELNE, v. 15, n. 1/2, p. 49-75, 2013.

.; BISPO, Edvaldo Balduino; SILVA, José Romerito. Linguística funcional centrada no uso. In: CEZARIO, Maria Maura; FURTADO DA CUNHA, Maria Angélica (Orgs.). Linguística centrada no uso: uma homenagem a Mário Martelotta. Rio de Janeiro: Mauad: FAPERJ, 2013, p. 13-39. 
FRIED, Mirjam. Constructions and constructs: mapping a shift between predication and attribution. In: BERGS, A. \& DIEWALDS, G. (Ed.). Constructions and language change. Berlin \& New York: Mount de Gruyter, 2008, p. 47-79

. Representing contextual factors in language change: between frames and constructions. In: BERGS, Alexander \& DIEWALD, Gabriele (Ed.). Contexts and constructions, 2009.

. Construction Grammar. In: ALEXIADOU, A.; KISS, T. (Ed.) Handbook of sintax. 2. ed. Berlin: Walter de Gruyter, 2015, p. 974-1003.

GIVÓN, Talmy. Funcionalism and grammar. Amsterdam/Philadelphia: John Benjamins, 1995.

GOLDBERG, Adele E. Constructions: a construction grammar approach to argument structure. Originally presented as the author thesis (Ph.D.). California: Unversitiy of California, 1995.

Constructions at work: the nature of generalization in language. Oxford: Oxford University Press, 2006.

LAKOFF, George; TURNER, Mark. More than cool reason: a field guide to poetic metaphor. Chicago/ London: CUP, 1989.

LAKOFF, George; JOHNSON, Mark. Philosophy in the flesh. New York: Basic Books, 1999.

MARTELOTTA, Mário Eduardo. Mudança Linguística: uma abordagem baseada no uso. São Paulo: Cortez, 2011.

OLIVEIRA, Jaciara Ornélia N.; OLIVEIRA, Mariangela Rios. O particípio presente em cartas de Bernardo de Claraval: mudança e conservação na língua portuguesa. Confluência Revista do Instituto de Língua Portuguesa. N 35/36 $2^{\circ}$ semestre de 2008/1º semestre de 2009. Rio de Janeiro, 2009.

OLIVEIRA, Mariangela Rios; ROSÁRIO, Ivo da Costa. Funcionalismo e abordagem construcional da gramática. Alfa, São Paulo, 60 (2), p. 233-259, 2016.

SILVA, José Romerito. Adjetivação e gêneros discursivos: uma proposta de contribuição à leitura e à produção de textos. Comunicação Individual apresentada no VI Simpósio Internacional de Estudos sobre Gêneros Textuais e Ensino (SIGET). Natal-RN, 2011.

TAVARES, Maria Alice. Os conectores e, ai e então na sala de aula. In: FURTADO DA CUNHA, Maria Angélica; TAVARES, Maria Alice. Funcionalismo e ensino de gramática. Natal: EDUFRN, 2007.

TOMASELLO, M (Ed.). The new psychology of language. New Jersey: Lawrence Erlbaum, v. $1,1998$.

TRAUGOTT, Elizabeth C. (Inter)subjectivity and (Inter)subjectification: a reassessment. In:

DAVIDSE, Kristin; VANDELANOTTE, Lieven; CUYCKENS, Hubert. (Eds.). Subjectification, intersubjectification and grammaticalization. Berlin/New York: Walter de Gruyter, 2010, p. 29-71. 
; DASHER, Richard B. Regularity in semantic change. Cambridge: Cambridge University Press, 2002.

VOTRE, Sebastião J.; OLIVEIRA, Mariangela Rios de. Corpus Discurso \& Gramática - a língua falada e escrita na cidade do Rio de Janeiro. Rio de Janeiro: UFRJ, 1995. (impresso)

Recebido em 25/07/2017

Aceito em 25/08/2017

Publicado em 28/08/2017 